\title{
GESTÃO DE RESÍDUOS EMPREGANDO COMPOSTAGEM: UMA ABORDAGEM ANALÍTICA DAS PUBLICAÇÕES NACIONAIS
}

Márcia Aparecida Andreazzi ${ }^{1}$ Sandra Maria Simonelli ${ }^{2}$ Maria de los Angeles Perez Lizama ${ }^{3}$ Eliane da Silva Fernandes ${ }^{4}$ Natália Christina da Silva Matos ${ }^{5}$

${ }^{1}$ Profa Dra do Curso de Medicina Veterinária e do Mestrado em Tecnologias Limpas do Centro Universitário de Maringá/ UNICESUMAR, Maringá, Paraná, Brasil (marcia.andreazzi@unicesumar.edu.br). Bolsita ICETI/ Unicesumar.

${ }^{2}$ Profa Dra do Curso de Zootecnia da Universidade Estadual de Londrina UEL, Londrina, Paraná, Brasil

${ }^{3}$ Profa Dra do Curso de Ciências Biológicas e do Mestrado em Tecnologias Limpas do Centro Universitário de Maringá/ UNICESUMAR, Maringá, Paraná, Brasil Bolsita ICETI/ Unicesumar.

${ }^{4}$ Bióloga, aluna de doutorado em Ecologia de Ambientes Aquáticos Continentais da Universidade estadual de Maringá, Paraná, Brasil

${ }^{5}$ Aluna do Mestrado em Tecnologias Limpas do Centro Universitário de Maringá UNICESUMAR, Maringá, Paraná, Brasil.

Recebido em: 08/04/2017 - Aprovado em: 10/06/2017 - Publicado em: 20/06/2017 DOI: 10.18677/EnciBio_2017A60

\section{RESUMO}

Devido a atual preocupação brasileira e mundial com o meio ambiente e os avanços na gestão ambiental torna-se relevante evidenciar a situação dos estudos científicos publicados no Brasil. Portanto, o objetivo deste trabalho foi realizar uma abordagem analítica histórica e quantitativa da literatura científica nacional sobre gestão de resíduos empregando a técnica de compostagem. Foram levantados dados, entre os anos de 1995 e 2015 em periódicos indexados na base Scientific Eletronic Library Online (SCIELO). Os resultados mostraram que as pesquisas envolvem diferentes substratos e objetivos. Deve-se ressaltar que o acréscimo de publicações a partir de 2006 e, de forma mais significativa, a partir de 2011, coincide com o período de ratificação das premissas do Protocolo de Kyoto e com o maior número de publicações sobre compostagem com dejetos da suinocultura, uma atividade que gera impacto ambiental que requer estudos constantes e essenciais sobre gestão de resíduos.

PALAVRAS-CHAVE: estudos científicos; meio ambiente; tecnologias limpas.

\section{WASTE MANAGEMENT EMPLOYING COMPOSTING: A ANALYTICAL APPROACH OF THE NATIONAL PUBLICATIONS}

\footnotetext{
ABSTRACT

Due to current Brazilian and concern worldwide for the environment and advances in environmental becomes relevant to highlight the situation of scientific studies ENCICLOPÉDIA BIOSFERA, Centro Científico Conhecer - Goiânia, v.14 n.25; p.756 
publishing in Brazil. Therefore, the aim for this work was perform a conduct a historical and quantitative approach to national scientific literature about waste management employing the composting technical. Data were collected between the years 1995 and 2015 in periodic indexed in the Scientific Eletronic Library Online basis (SCIELO). The results have shown that the researches involve different substracts and aims. This important to enhance that the increase of publications from 2006 and, more significantly from 2011, coincides with the ratification period of premises of the Kyoto Protocol and with great number of publications about composting with waste of pig farming, a activity with great environmental impact that requires constants and essentials studies about residues management.

KEYWORDS: scientific studies; environment; clean technologies.

\section{INTRODUÇÃO}

PACKER (2014) afirmou que os periódicos científicos brasileiros publicaram, a partir de 2009, mais de um terço da produção científica e estes números de publicações deram ao Brasil a 13 ${ }^{a}$ posição na classificação internacional de produção científica. Neste contexto, é pertinente avaliar a quantidade e qualidade destas publicações. Para tanto, existem várias técnicas que podem ser utilizadas, tais como bibliometria, cienciometria, informetria e webometria (VANTI, 2002), que evidenciam a atividade científica e tecnológica de um determinado assunto ao longo dos anos.

Considerando a atual e concernente preocupação com o meio ambiente e os avanços na gestão ambiental e de resíduos, analisar e conhecer a atual situação das publicações referentes a estes temas se faz necessário. Análises das publicações sobre compostagem, uma importante prática na gestão de resíduos e na busca pela sustentabilidade ambiental (HEN et al. 2013), permitirão evidenciar as diferentes direções das investigações sobre este assunto, os objetivos e os principais materiais empregados, entendendo seu comportamento científico.

O Plano Nacional de Resíduos Sólidos, de setembro de 2011 (BRASIL, 2011), elenca e enfatiza como destinação adequada para vários resíduos o emprego de biodigestores e a compostagem, dentre outras tecnologias. Complementando estas informações, a Lei $n^{\circ}$ 12.305, que instituiu a Política Nacional de Resíduos Sólidos (BRASIL, 2010), descreve como destinação final de resíduos ambientalmente adequada aquelas que evolvem a reutilização, a reciclagem, a compostagem, a recuperação e o aproveitamento energético ou outras destinações admitidas pelos órgãos competentes.

Segundo HECK et al. (2013), a compostagem compreende a fase termofílica, responsável pela degradação ativa do material, seguida da fase de maturação ou cura. Ao final do processo, é gerado um material rico em nutrientes, que pode ser usado como adubo nos solos. Segundo os autores HEN et al., (2013) a compostagem é uma tecnologia limpa, capaz de reciclar materiais indesejáveis, convertendo-os em material estável que pode ser devolvido ao solo, sem prejuízos ao ambiente.

O objetivo deste trabalho foi realizar uma abordagem analítica histórica, quali e quantitativa da literatura científica nacional, sobre a gestão de resíduos empregando a técnica da compostagem, empregando ferramentas como quantidade de artigos em função do tempo, da região e de substratos empregados. 


\section{MATERIAL E MÉTODOS}

O objeto de análise foi a produção científica veiculada em periódicos indexados nos bancos de dados da Scientific Eletronic Library Online (SciELO), disponível na Biblioteca Virtual por meio do site http://www.scielo.org.

A busca dos artigos científicos foi realizada nos meses de novembro de 2015 a janeiro de 2016 e para isso foi utilizado o descritor "compostagem". O processo de busca, no primeiro momento, permitiu a identificação de 106 artigos científicos. Em seguida, os trabalhos científicos foram selecionados por meio da avaliação dos títulos e resumos. Os mesmos obedeceram aos seguintes critérios de inclusão: publicações datadas no período compreendido entre 1995 e 2015 e estarem relacionados ao emprego da técnica de compostagem no Brasil, sob a ótica da destinação de resíduos ambientalmente adequada. Desta forma, foram excluídos 17 trabalhos, tidos como sem aderência à pesquisa ou cujo descritor foi empregado em temáticas não relacionadas ao tema central desta pesquisa, o que resultou em 88 artigos.

Após avaliação dos 88 trabalhos, que atenderam aos critérios de seleção e análise crítica, foram identificados e coletadas as seguintes informações: ano de publicação do artigo científico, que permitiu obter o número de artigos publicados em função dos anos, eixo temático central da pesquisa, que em função da diversidade foi dividido de acordo com os principais objetivos das pesquisas: animal, vegetal, animal e vegetal, lixo urbano, lodo, vermicompostagem, equipamentos e gestão de resíduos; cidade e estado de origem do autor principal do trabalho e classificação do periódico segundo o critério Qualis/ CAPES, na área de Ciências Ambientais.

Os dados foram tabulados e organizados em planilhas do programa Microsoft Excel 2010 e foi empregada análise descritiva dos dados. Para a obtenção de resultados mais robustos, foi utilizada a Correlação por Postos de Spearman ("rs") entre o número de publicações e o período analisado. O teste não-paramétrico de Kruskal-Wallis ("H") foi utilizado para analisar possíveis diferenças entre o número de publicações de cada Qualis (A1, A2, B1, B2, B4 e sem Qualis). Como periódicos com Qualis B3 não foram encontrados, não fizeram parte da análise. As análises estatísticas foram realizadas por meio do Software Bioestat 5.

\section{RESULTADOS E DISCUSSÃO}

O estudo quali e quantitativo permitiu identificar o número de artigos publicados na base de dados SciELO, de acordo com o ano de publicação, no período compreendido entre os anos de 1995 a 2015. Os resultados possibilitaram observar que as publicações sobre compostagem se iniciaram a partir de 1995 (Figura 1). Dentre os períodos analisados, houve aumento dos números de publicações sobre a técnica de compostagem no Brasil em função dos anos.

PROSCHNOW et al. (1995) publicaram o primeiro estudo sobre compostagem no Brasil, que teve o propósito de avaliar a eficiência do gesso agrícola e superfosfato em controlar as perdas de amônia durante o processo de compostagem de esterco. Após três anos, CRAVO et al. (1998) fizeram uma caracterização química dos compostos de lixo urbano de diversas usinas no Brasil. Um ano após, foi publicado o estudo de JAHNEL et al. (1999), que avaliaram o processo de compostagem com lixo urbano. No ano de 2000 , o foco de estudo foi se ampliando, dando destaque ao lixo urbano e a vermicompostagem de dejetos animais (MANGRICH et al., 2000). A partir de 2005, as publicações científicas sofreram um aumento significativo, evidenciando objetivos diversos (COSTA et al., 2005; SILVA et al., 2008; CARRA et al., 2013; LEAL et al., 2013; HECK et al., 2013; GIACOMINI ENCICLOPÉDIA BIOSFERA, Centro Científico Conhecer - Goiânia, v. 14 n.25; p.758 
et al., 2014; GOMES et al., 2014; CESTONARO et al., 2014; FUJl et al., 2014; COTTA et al., 2015; GOMES et al., 2015).

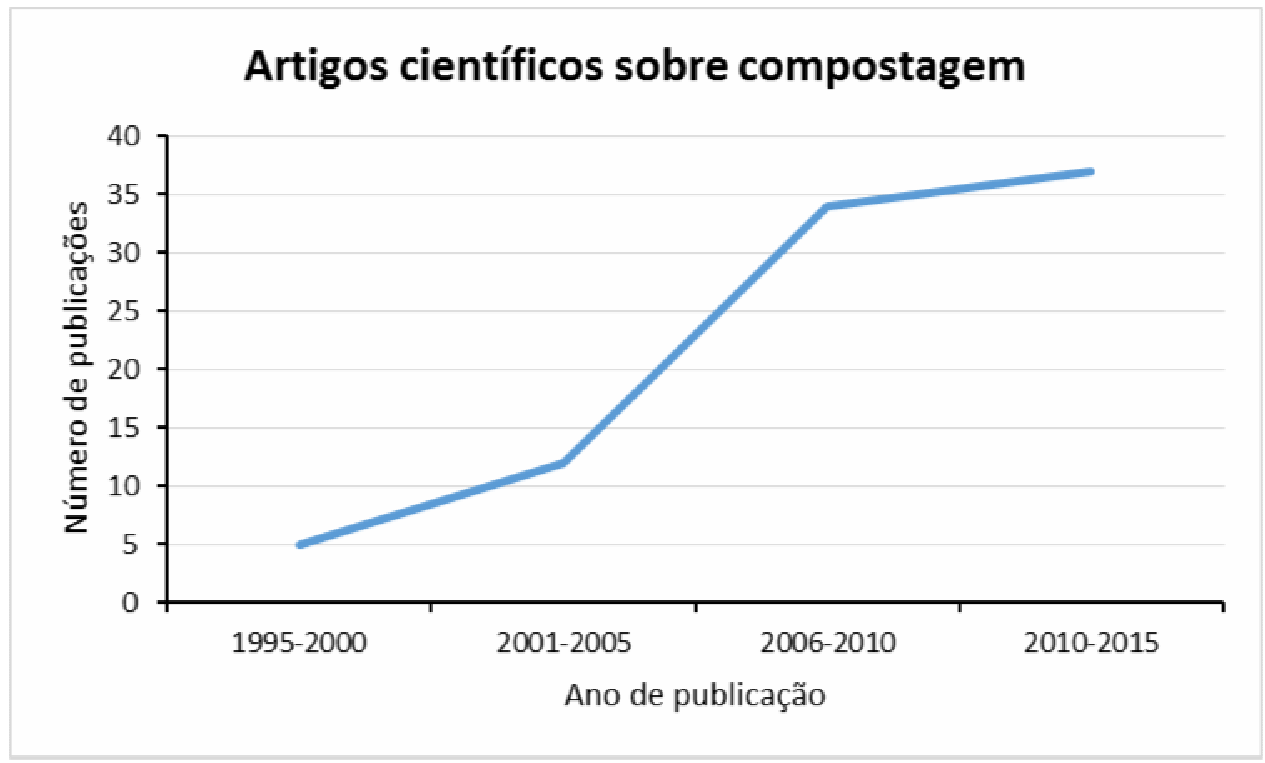

FIGURA 1. Número de artigos científicos publicados no Brasil, sobre compostagem, entre os anos de 1995 e 2015

Este aumento no número de publicações a partir de 2005 pode ser explicado baseado nas afirmativas de MARTINE \& ALVES (2015) e na evolução da discussão ambientalista, que foi marcada por três fases distintas: a I Conferência das Nações Unidas Para o Meio Ambiente Humano, realizada em Estocolmo, que contribuiu para o entendimento sobre os problemas ambientais e de subsistência da sociedade (BARBIERI, 2004), e a publicação do Relatório "Limites do Crescimento", elaborado pelo Clube de Roma, em 1968; a segunda fase envolve a elaboração do Relatório "Nosso Futuro Comum", publicado pela Comissão Mundial para o Desenvolvimento e Meio Ambiente, criada pela ONU, em 1987, e a terceira e última fase compreende a Conferência das Nações Unidas para o Meio Ambiente e Desenvolvimento, realizada no Rio de Janeiro, em 1992 e a elaboração e aprovação do Protocolo de Kyoto, em 1997.

O objetivo do Protocolo era a redução de, em média, 5,2\%, das emissões de gases de efeito estufa, entre os anos de 2008 e 2012. Contudo, apesar de ter sido aprovado no ano de 1997, o Protocolo de Kyoto só foi ratificado juridicamente para os 141 países signatários, em 16 de fevereiro de 2005, com o objetivo de definir metas consistentes contra o aquecimento global do planeta. Sendo assim, torna-se evidente o aumento do número de publicações associadas ao período de ratificação do Protocolo de Kyoto. De fato, BARBIERI (2004) afirmou que o Protocolo foi um avanço na gestão ambiental, pois fixou metas e criou mecanismos importantes para implementá-las, tais como, a Implementação Conjunta, Comércio de Emissões e Mecanismo de Desenvolvimento Limpo.

Com relação ao eixo temático, o levantamento mostrou ampla variação quanto ao tipo de material compostado ou quanto ao objetivo do emprego da técnica (Figura 2). A análise revelou trabalhos que visaram o emprego da compostagem com resíduos de origem animal, vegetal, ambos, com lixo urbano, lodo (cortume, esgoto 
e têxtil), comparações entre o emprego da técnica de compostagem e de vermicompostagem e análises de eficácia de equipamentos para composteiras, além de algumas revisões sobre o assunto.

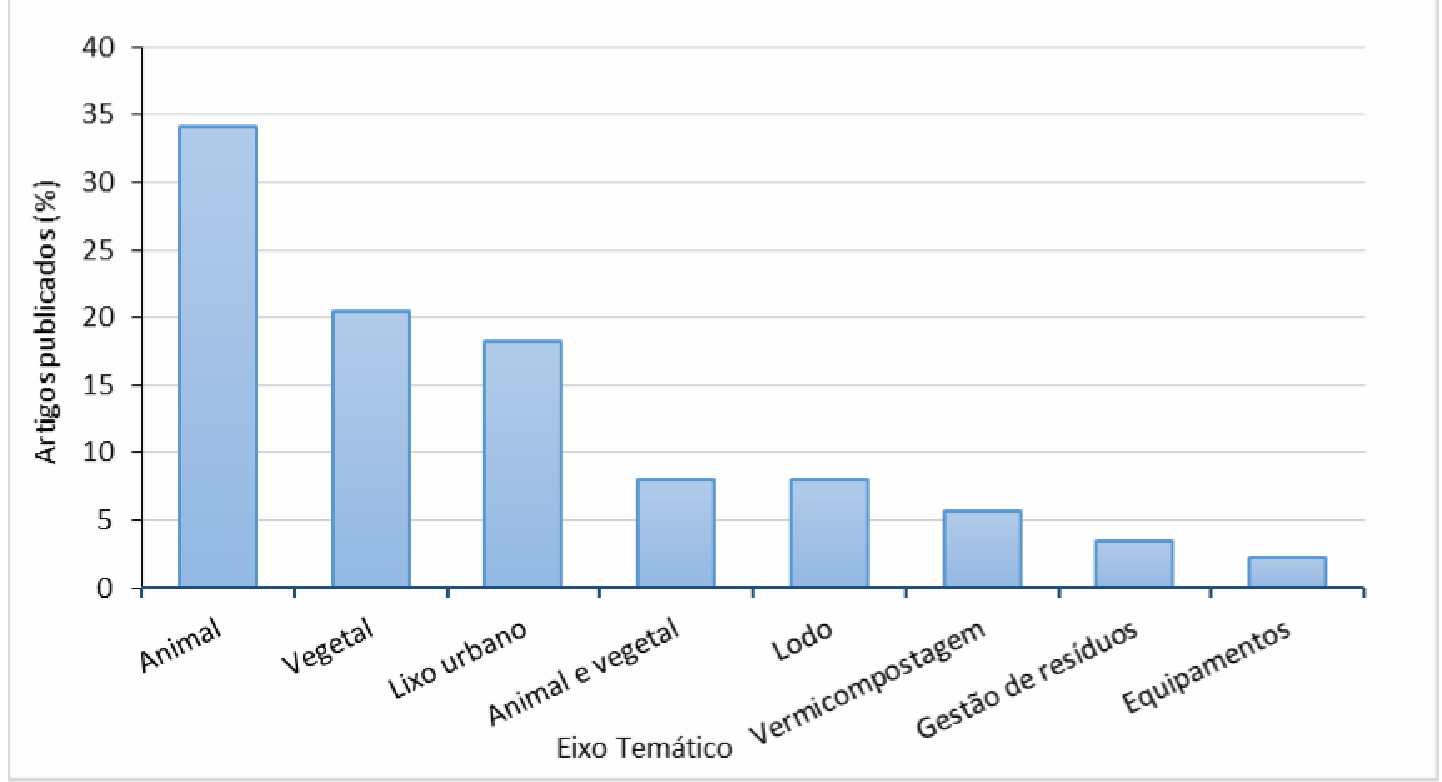

FIGURA 2. Porcentagem de artigos científicos publicados no Brasil, sobre compostagem, de acordo com o eixo temático, entre os anos de 1995 e 2015.

É possível observar que a maioria dos artigos (34\%) é na área de compostagem com substratos de origem animal, por isso, visando um maior detalhamento deste eixo, os artigos foram classificados de acordo com o tipo de substrato (Tabela 1 ).

Os resultados destacaram que $26,67 \%$ destas publicações envolvem dejetos suínos. De fato, a suinocultura brasileira está bem consolidada, colocando o Brasil como $4^{\circ}$ maior produtor e exportador de carne suína no âmbito mundial. Segundo RIZZONI et al., (2012) a suinocultura é considerada, pelos órgãos de controle ambiental, a atividade agropecuária que ocasiona maior impacto ambiental. Os dejetos suínos são constituídos por fezes, urina, água residual, ração, pelos, poeira e outros materiais (RIZZONI et al., 2012; GOMES et al., 2014) e correspondem, em termos comparativos, a quatro vezes o equivalente populacional humano. A crescente expansão desta atividade desperta a necessidade de estudos sobre a destinação correta dos dejetos e resíduos desta cadeia.

Em concordância com esta necessidade pela busca por detinações corretas, a Lei $N^{0}$ 12.305, que instituiu a Política Nacional de Resíduos Sólidos (BRASIL, 2010), lista como destinação final ambientalmente adequada a reutilização, a reciclagem, a recuperação e o aproveitamento energético e a compostagem (MANNARINO et al., 2016). Este fato comprova que as publicações sobre compostagem de dejetos de suínos são fundamentais na atualidade

Aproximadamente $17 \%$ do total de publicações registradas neste estudo se referiam a área de compostagem de carcaças de aves mortas. De fato, sabe-se que criações de frangos de corte geram resíduos, como a cama e as aves mortas, que 
devem ser tratados de forma ambientalmente correta. Em função do crescimento expressivo desta cadeia produtiva no Brasil, a gestão das carcaças de aves mortas merece destaque.

TABELA 1. Porcentagem de artigos científicos publicados no Brasil, sobre compostagem, de acordo com a espécie animal e material compostado ( $\mathrm{n}: 30$ ), entre os anos de 1995 e 2015.

\begin{tabular}{lc}
\hline Espécie animal e material compostado & Artigos publicados (\%) \\
\hline Aves & 3,33 \\
$\quad$ Dejetos & 16,67 \\
$\quad$ Carcaça & 6,67 \\
$\quad$ Resíduos de Abatedouro & \\
Suínos & 26,67 \\
$\quad$ Dejetos & \\
Bovinos & 13,33 \\
$\quad$ Dejetos & 3,33 \\
$\quad$ Carcaça & 6,67 \\
$\quad$ Resíduos de abatedouro & \\
Cocompostagem & 10,00 \\
$\quad$ Dejetos de aves e de bovinos & \\
Caprinos & 6,67 \\
$\quad$ Dejetos & \\
Ovinos & 3,33 \\
$\quad$ Dejetos & \\
Equinos & 3,33 \\
$\quad$ Cama com dejetos & $\mathbf{1 0 0 , 0 0}$ \\
\hline Total $\quad$
\end{tabular}

A busca por alternativas para a disposição das carcaças de aves mortas é um desafio ambiental e de biossegurança, por isso a técnica da compostagem é a forma mais adequada. ANDREAZZI et al. (2014) observaram vários problemas quanto ao emprego desta técnica, entretanto, os autores afirmaram que orientações simples aos produtores podem resolver estes problemas e assegurar o sucesso, garantindo uma segurança biológica e ambiental. Desta forma, os achados evidenciam que vários pesquisadores estão preocupados e que investigam e publicam sobre gestão de resíduos empregando a compostagem na cadeia produtiva do frango de corte.

Os resultados também mostraram alta porcentagem de publicações que referenciaram dejetos de bovino e a cocompostagem (dejetos de bovinos e de aves), totalizando $20,30 \%$. Estas publicações manifestaram o emprego da compostagem visando a produção de um material rico em nutrientes que pode ser usado como substrato ou como adubo em diferentes culturas (HECK et al, 2013).

Contudo, existe ainda a necessidade de trabalhos nesta área, pois vários fatores podem influenciar o processo. Para se obter um composto que possa ser utilizado de forma segura e eficiente, este deve estar estabilizado, livre de patógenos e conter quantidades mínimas de componentes tóxicos e contaminantes (SIQUEIRA \& ASSAD, 2015). Baseados nestas colocações, credita-se estas publicações à 
comprovações e estudos que visam assegurar o emprego do composto gerado no processo.

A análise quanto a origem dos autores dos artigos científicos (Tabela 2) permitiu identificar que pesquisadores de vários estados estudam o tema, porém, o estado de São Paulo se destaca com o maior número de contribuições $(30,76 \%)$, seguido pelos estados de Minas Gerais (12,80\%), Paraná (11,53\%) e Rio Grande do Sul $(11,53 \%)$. Com efeito, este achado reforça a classificação de publicações das principais universidades no Brasil, onde várias universidades paulistas se destacam quanto ao número de publicações científicas.

TABELA 2. Porcentagem de artigos científicos publicados no Brasil, sobre compostagem, de acordo com o estado do primeiro autor, entre os anos de 1995 e 2015.

\begin{tabular}{cc}
\hline Estado do primeiro autor & Artigos publicados (\%) \\
\hline São Paulo & 30,68 \\
Minas Gerais & 13,64 \\
Rio Grande do Sul & 12,50 \\
Paraná & 10,23 \\
Goiás & 5,68 \\
Outros estados $^{1}$ & 21,59 \\
Outros países $^{2}$ & 3,41 \\
\hline TOTAL $^{2}$ & $\mathbf{1 0 0 , 0 0}$
\end{tabular}

Os outros estados de origem do primeiro autor do artigo foram, por estado, Rio de Janeiro, Santa Catarina, Piauí, Bahia, Alagoas, Amazonas, Espírito Santo, Mato Grosso, Paraíba, Pernambuco, Rio Grande do Norte e Ceará, com menos de 3 artigos por estado. ${ }^{2}$ Os outros países de origem do primeiro autor foram, somente com uma publicação por país, China, Colômbia e Portugal.

A evidência da maior contribuição oriunda do estado de São Paulo (30,68\%), refletiu no maior detalhamento deste eixo, por isso, os artigos foram classificados de acordo com a cidade de origem do primeiro autor. Os resultados encontrados permitiram observar que muitas cidades paulistas estão envolvidas com estudos referentes ao tema, contudo, duas cidades se destacaram: Jaboticabal (33,33\%, n:9) e Piracicaba $(29,63 \%, n: 8)$. Admite-se este resultado ao fato de que, nestas duas cidades, existem Universidades que desenvolvem muitas pesquisas, dentre elas, pesquisas na área gestão de resíduos.

Considerando a classificação dos periódicos científicos segundo o critério Qualis, instituído pela Coordenação de Aperfeiçoamento de Pessoal de Nível Superior (CAPES), fundação do Ministério de Educação e Cultura (MEC) na área de Ciências Ambientais, foi possível observar que 78 artigos científicos sobre compostagem selecionados na presente pesquisa, procederam de periódicos científicos classificados com os melhores estratos. Identificou-se que a maioria foi publicada em periódicos classificadas com estrato Qualis B1 em Ciências Ambientais, seguida, em ordem, pelos Qualis A2, B2 e A1 (Figura 3). 


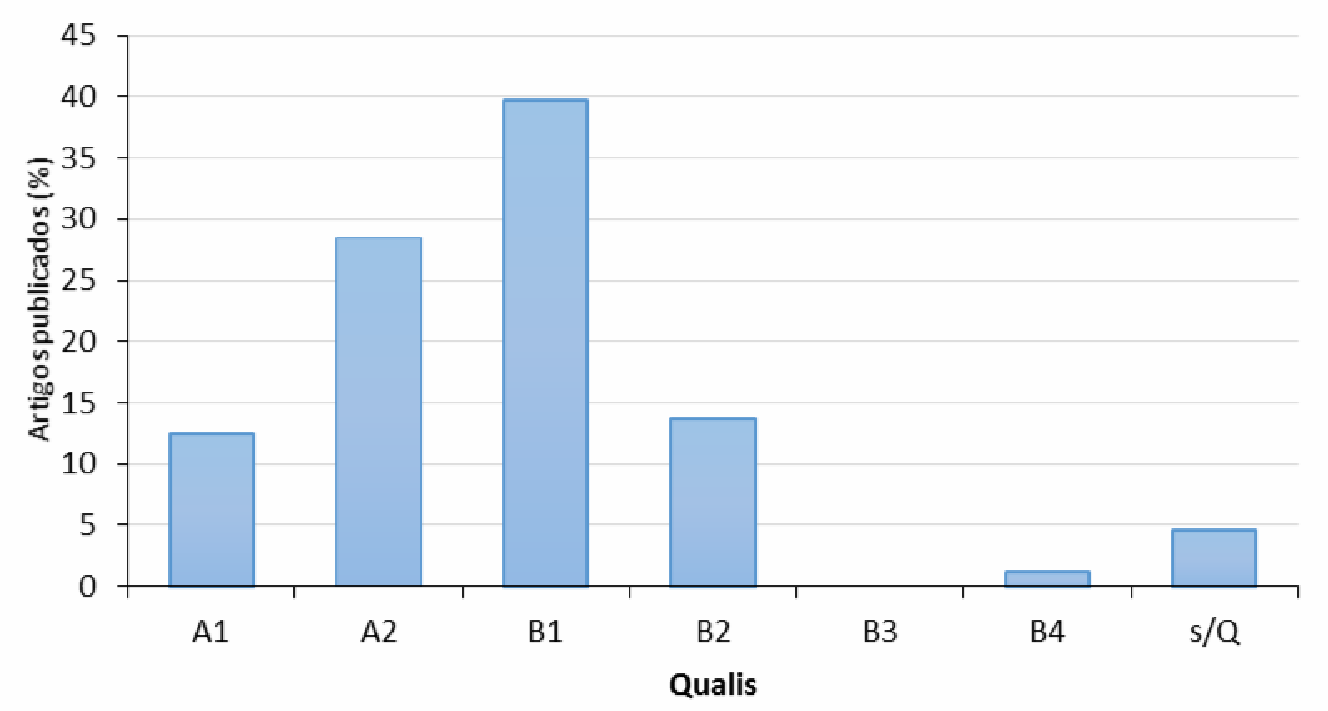

FIGURA 3. Porcentagem de artigos publicados no Brasil sobre compostagem, segundo o critério Qualis, na área de Ciências Ambientais, analisados entre os anos de 1995 e 2015.

Ao longo do período analisado, foram verificadas diferenças significativas $(H=20.04 ; p=0.0012)$ entre os estratos Qualis das publicações. Essas diferenças foram maiores entre A2 (com números crescentes nos anos de 2006 à 2015) e B4 (apenas um artigo publicado no ano de 2015); e B1 (com números crescentes entre 2005 a 2015) e B4. As revistas com Qualis A2 e B1 tiveram maior número de artigos publicados durante os anos de 2006 a 2015 (Figura 4).

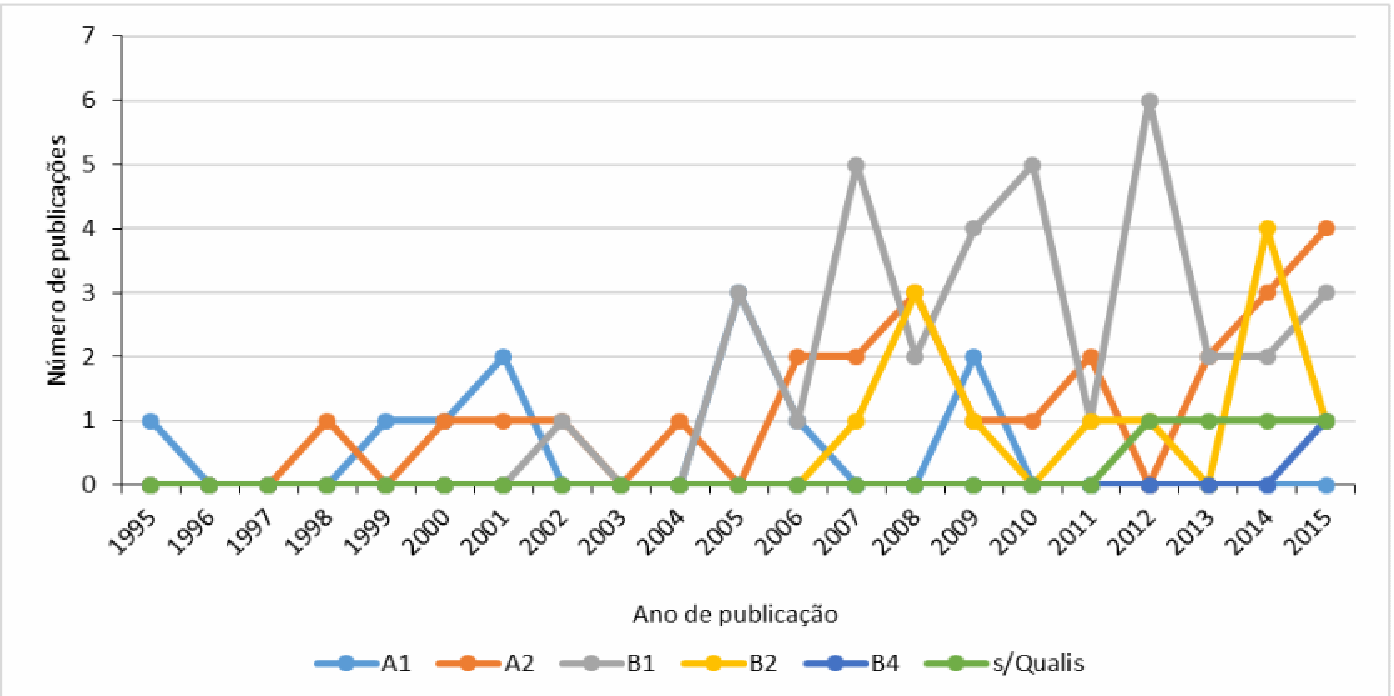

FIGURA 4. Número de artigos publicados no Brasil sobre compostagem, segundo o critério Qualis, na área de Ciências Ambientais, analisados entre os anos de 1995 e 2015.

A área de Ciência Ambientais, criada pela CAPES em 2011, surgiu em função da necessidade de pesquisas que visem estudar a complexidade dos problemas 
ambientais. O Documento de Área (BRASIL, 2016) confirma que os estudos sobre a natureza complexa da problemática ambiental visam transpor desafios teóricos e metodológicos e vinculam-se a temas como água, energia, segurança alimentar, agricultura, dentre outros, comprovando que o tema desta análise apresenta maior aderência com esta área.

\section{CONCLUSÃO}

A abordagem histórica, analítica quali e quantitativa da literatura científica nacional sobre gestão de resíduos empregando compostagem permitiu identificar que as publicações sobre o tema em periódicos científicos no Brasil são muito variáveis, envolvendo diferentes objetivos, produtos e segmentos. Contudo, destacase a coincidência entre o acréscimo de publicações, a partir de 2006 e, de forma mais significativa, a partir de 2011, com a ratificação das premissas do Protocolo de Kyoto. A maioria dos artigos levantados reporta o emprego de compostagem com substrato de origem animal, sobretudo com dejetos suínos, porém, independente do substrato compostado, a temática comum em todos os trabalhos foi o emprego da compostagem como forma de gestão de resíduos ambientalmente correta.

\section{REFERÊNCIAS}

ANDREAZZI, M.A.; CHRISTÓFOLI, G.; SANTOS, J.M.G.; RIBEIRO, R.M.; EMANUELLI, I.P. Estudo sobre a qualidade das compostagens de aves mortas na região noroeste do Paraná. Enciclopédia Biosfera, Centro Científico Conhecer/ Goiânia, v.10, n.18, p. 1649-1657, 2014. Disponível em <http://www.conhecer.org.br/enciclop/2014a/AGRARIAS/estudo\%20sobre\%20a\%20 qualidade.pdf>

BARBIERI, J. C. Gestão ambiental empresarial: conceitos, modelos e instrumentos. 1.ed. São Paulo: Saraiva, 2004.

BRASIL. Minuta do Documento de Área 2016- Ciência Ambientais. Coordenação de Aperfeiçoamento de Pessoal de Nível Superior (CAPES). Disponível em: $<$ https://www.capes.gov.br/images/stories/download/avaliacao/49.camb_DOCUMEN TO_REA.pdf>

BRASIL. Plano Nacional de Resíduos Sólidos. Brasília, DF, 2011. Disponível em: <http://www.mma.gov.br/estruturas/253/_publicacao/253_publicacao0202201204175 7.pdf>

BRASIL. Política Nacional de Resíduos Sólidos, Lei 12.305. Diário Oficial da República Federativa do Brasil, Brasília, DF, 2010. Disponível em: <www.planalto.gov.br/ccivil_03/_ato2007-2010/.../lei/l12305.htm>. Acesso: jan. 2017.

CARRA, T.A.; CONCEIÇÃO, F. T.; TEIXEIRA, B.B. Indicadores para a gestão de resíduos sólidos em aeroportos e sua aplicação no Aeroporto Internacional de Viracopos, Campinas, São Paulo. Engenharia Sanitaria e Ambiental, v.18, n.2, p.131-138, 2013. Disponível em: <http://dx.doi.org/10.1590/S141341522013000200005>. doi:10.1590/S1413-41522013000200005

CEStONARO, T.; ABREU, P. G.; ABREU, V. M. N.; LOPES, L. S.; COLDEBELLA, A. Poultry carcass decomposition and physicochemical analysis of compounds in ENCICLOPÉDIA BIOSFERA, Centro Científico Conhecer - Goiânia, v.14 n.25; p.764 
different composter types. Engenharia Agrícola, v.34, n.4, p.617-625, 2014. Disponível em: <http://dx.doi.org/10.1590/S0100-69162014000400002>. doi:10.1590/S0100-69162014000400002

COSTA, M. S. S. M.; COSTA, L. A. M.; SESTAK, M.; OLIBONE, D.; SESTAK, D.; KAUFMANN, A.; ROTTA, S. R. Compostagem de resíduos da indústria de desfibrilação de algodão. Engenharia Agrícola, v.25, n.2, p.540-548, 2005. Disponível em: <http://dx.doi.org/10.1590/S0100-69162005000200028>. doi:10.1590/S0100-69162005000200028

COTTA, J. A. O.; CARVALHO, N.N.L.C.; BRUM, T.S.; REZENDE, M.O.O. Compostagem versus vermicompostagem: comparação das técnicas utilizando resíduos vegetais, esterco bovino e serragem. Engenharia Sanitária e Ambiental, v.20, n1, p.65-78, 2015. Disponível em: <http://dx.doi.org/10.1590/S141341522015020000111864>. doi:10.1590/S1413-41522015020000111864

CRAVO, M.S.; MURAOKA, T.; GINE, M.F. Caracterização química de compostos de lixo urbano de algumas usinas brasileiras. Revista Brasileira de Ciencias do Solo, v.22, n.3, p. 547-553, 1998. Disponível em: <http://dx.doi.org/10.1590/S010006831998000300021>. doi:10.1590/S0100-06831998000300021

FUJII, K. Y.; DITTRICH, J. R.; CASTRO, E. A.; SILVEIRA, E. O. Processos de tratamento de resíduos de cocheira e a redução ou eliminação de ovos e larvas infectantes do gênero Strongylus spp.. Arquivos do Instituto Biológico, v.81, n.3, p.226-231, 2014. Disponível em: <http://dx.doi.org/10.1590/1808-1657000482012>. doi:10.1590/1808-1657000482012

GIACOMINI, D.A.; AITA, C.; PUJOL, S. B.; GIACOMINI, S. J.; DONEDA, A.; CANTÚ, R.R.; DESSBESELL, A.L.; LÜDTKE, R.C.; SILVEIRA, C.A.P. Mitigação das emissões de amônia por zeólitas naturais durante a compostagem de dejetos de suínos. Pesquisa Agropecuária Brasileira, v.49, n.7, p.521-530, 2014. Disponível em: <http://dx.doi.org/10.1590/S0100-204X2014000700004> doi:10.1590/S0100204X2014000700004

GOMES, L. P.; PERUZATTO, M.; SANTOS, V. S.; SELLITTO, M. A. Indicadores de sustentabilidade na avaliação de granjas suinícolas. Engenharia Sanitária e Ambiental. v.19, n.2, 2014. Disponível em: <http://dx.doi.org/10.1590/S141341522014000200005> doi:10.1590/S1413-41522014000200005

GOMES, L.P.; KOHL, C.A.; SOUZA, C.L.L.; REMPEL, N.; MIRANDA, L.A.S.; MORAES, C.A.M. Avaliação ambiental de aterros sanitários de resíduos sólidos urbanos precedidos ou não por unidades de compostagem. Engenharia Sanitaria e Ambiental, v.20, n3, p.449-462, 2015. Disponível em: < http://dx.doi.org/10.1590/S1413-41522015020000120751>. doi:10.1590/S141341522015020000120751

HECK, K. M.; ÉVILIN G.; HAHN, A.B.B.; KLUGE, M.; SPILKI, F.; VAN DER SAND, S.T. Temperatura de degradação de resíduos em processo de compostagem e qualidade microbiológica do composto final. Revista Brasileira de Engenharia Agrícola e Ambiental, v.17, n.1, p.54-59, 2013. Disponível em: ENCICLOPÉDIA BIOSFERA, Centro Científico Conhecer - Goiânia, v.14 n.25; p.765 2017 
HEN, J. D.; SANTOS FILHO, J.I.; NOVAES, M. et al. Relatório de Avaliação de Impacto de Tecnologia Gerada pela EMBRAPA Suínos e Aves: Composteira de Carcaças de Suínos. Concórdia: EMBRAPA Suínos e Aves, 2013.

JAHNEL, M.C.; MELLONI, R.; CARDOSO, E.J.B.N. Maturidade de composto de lixo urbano. Scientia Agricola, v.6, n.2, p. 301-304, 1999. Disponível em <http://dx.doi.org/10.1590/S0103-90161999000200007> doi:10.1590/S010390161999000200007

LEAL, M. A.; GUERRA, J. G. M.; ESPINDOLA, J. A. A.; ARAUJO, E.S. Compostagem de misturas de capim-elefante e torta de mamona com diferentes relações C:N. Revista Brasileira de Engenharia Agrícola e Ambiental. v.17, n.11, 2013. Disponível em: <http://dx.doi.org/10.1590/S1415-43662013001100010> doi:10.1590/S1415-43662013001100010

MANGRICH, A.S.; LOBO, M.A.; TANCK, C.B; WYPYCH, F.T.; EDINA, B. S.; GUIMARÃES, E. Criterious preparation and characterization of earthworm-composts in view of animal waste recycling. Part I. Correlation between chemical, thermal and FTIR spectroscopic analyses of four humic acids from earthworm-composted animal manure. Journal of the Brazilian Chemical Society, v.11, n.2, p. 164-169, 2000. Disponível em: <http://dx.doi.org/10.1590/S0103-50532000000200011> doi:10.1590/S0103-50532000000200011

MANNARINO, C. F.; FERREIRA, J. A.; GANDOLLA, M. Contribuições para a evolução do gerenciamento de resíduos sólidos urbanos no Brasil com base na experiência Européia. Engenharia Sanitaria e Ambiental, v.21, n.2, p.379-385, 2016. Disponível em: < http://dx.doi.org/10.1590/s1413-41522016146475> doi:10.1590/s1413-41522016146475

MARTINE, G.; ALVES, J. E. D. Economia, sociedade e meio ambiente no século 21: tripé ou trilema da sustentabilidade? Revista Brasileira de Estudos de População, v.32, n.3, p.433-460. 2015. Disponível em: <http://dx.doi.org/10.1590/S01023098201500000027>. doi:10.1590/S0102-3098201500000027

PACKER, A. L. A eclosão dos periódicos do Brasil e cenários para o seu porvir. Educação e Pesquisa. v.40, n.2, p.301-323, 2014. Disponível em: < http://dx.doi.org/10.1590/S1517-97022014061860> doi:10.1590/S151797022014061860

PROCHNOW, L.I.; KIEHL, J.C.; PISMEL, F.S.; CORRENTE, J.E. Controle de perdas de amônia durante a compostagem de estercos com adição de fosfogesso e superfosfato simples. Scientia Agricola, v.52, n.2, p. 346-349, 1995. Disponível em: <http://dx.doi.org/10.1590/S0103-90161995000200024> doi:10.1590/S010390161995000200024 
RIZZONI, L.B.; TOBIAS, A.C.T.; DEL BIANCHI, M.D.; GARCIA, J.A.D. Biodigestão anaeróbia no tratamento de dejetos de suínos. Revista Científica Eletrônica de Medicina Veterinária, v.9, n.18, p.1-20, 2012.

SILVA, A. G.; LeITE, V. D.; SILVA, M. M. P.; PRASAD, S.; FEITOSA, W. B. Compostagem aeróbia conjugada de lodo de tanque séptico e resíduos sólidos vegetais. Engenharia Sanitaria e Ambiental, v.13, n.4, p.371-379, 2008. Disponível em: < http://dx.doi.org/10.1590/S1413-41522008000400005>. doi:10.1590/S1413-41522008000400005

SIQUEIRA, T. M. O.; ASSAD, M. L. R. C. LOPES. Compostagem de resíduos sólidos urbanos no estado de São Paulo (BRASIL). Ambiente e Sociedade, v.18, n.4, 2015. Disponível em: < http://dx.doi.org/10.1590/1809-4422ASOC1243V1842015> doi:10.1590/1809-4422ASOC1243V1842015

VANTI, N.A.P. Da bibliometria à webometria: uma exploração conceitual dos mecanismos utilizados para medir o registro da informação e a difusão do conhecimento. Ciência da Informação, v.31, n.2, p. 152-162, 2002. Disponível em: <http://dx.doi.org/10.1590/S0100-19652002000200016> doi:10.1590/S010019652002000200016 